\title{
Reduced expression of FXYD domain containing ion transport regulator 5 in association with hypertension
}

\author{
XIAOYAN HUANG ${ }^{1}$, BENJI WANG $^{1}$, DEYE YANG $^{1}$, XIANGXIANG SHI $^{1}$, JIAN HONG $^{3}$, \\ SUYUN WANG ${ }^{1}$, XIAOCHUN DAI $^{1}, \mathrm{XI} \mathrm{ZHOU}^{1}$ and YONG-JIAN GENG ${ }^{2}$ \\ ${ }^{1}$ The First Affiliated Hospital, Wenzhou Medical College, Wenzhou 325000, P.R. China; ${ }^{2}$ University of Texas School \\ of Medicine at Houston and Texas Heart Institute, Houston, TX; ${ }^{3}$ Baylor College of Medicine, Houston, TX, USA
}

Received September 2, 2011; Accepted October 14, 2011

DOI: $10.3892 / \mathrm{ijmm} .2011 .837$

\begin{abstract}
Experimental evidence indicates that hypertension is a multifactorial disorder and that the products of several genes may contribute to its development. The aim of this study was to investigate the expression of hypertension-related genes in spontaneous hypertensive rats (SHRs). A microarray screening for hypertension-related genes was conducted in SHRs and Wistar-Kyoto (WKY) rats using total-RNA extracted from second-order mesenteric arteries and kidneys. The FXYD5 mRNA expression in vascular smooth muscle cells (VSMCs) was silenced by RNA interference (RNAi). Meanwhile, the FXYD5 mRNA overexpression in renal tubular epithelial cells (RTECs) was induced by the recombinant plasmid pcDNA3.1(+)-FXYD5. The expression of FXYD5 mRNA was found to be 14.8-fold lower in SHR rats compared to that in WKY rats $(\mathrm{P}<0.01)$. The levels of FXYD5 mRNA expression were the highest in kidneys of SHR 13-week-old rats when the blood pressure reached the highest levels. The down-regulated FXYD5 mRNA expression inhibited the migration of smooth muscle cells $(\mathrm{P}<0.01)$ and cell membrane $\mathrm{Na}^{+}-\mathrm{K}^{+}$-ATPase activity $(\mathrm{P}<0.01)$. Up-regulated FXYD5 mRNA expression enhanced the renal tubular epithelial cell membrane $\mathrm{Na}^{+}-\mathrm{K}^{+}-$ ATPase activity $(\mathrm{P}<0.05)$ and cell proliferation $(\mathrm{P}<0.05)$. FXYD5 is related to the migration of smooth muscle cells and cell membrane $\mathrm{Na}^{+}-\mathrm{K}^{+}$-ATPase activity in rodents. The results of the present study suggest that FXYD5 may have profound impact on the regulation of blood pressure, and that this gene may be a potential target for anti-hypertensive therapy.
\end{abstract}

Correspondence to: Dr Deye Yang, Department of Cardiology, The First Affiliated Hospital, Institute for Cardiovascular Biology and Gene, Wenzhou Medical College, Wenzhou 325000, P.R. China E-mail: deyeyang203@hotmail.com

Abbreviations: SHR, spontaneous hypertensive rat; WKY, normotensive Wistar-Kyoto rat; VSMCs, vascular smooth muscle cells; RTECs, renal tubular epithelial cells; FXYD5, homolog FXYD domain containing ion transport regulator 5

Key words: hypertension, rodent, ion channel, ion transport regulator, RNA interference, eukaryotic expression vector

\section{Introduction}

The prevalence of hypertension has been reported to be $21.1 \%$ among Canadians $>18$ years old and $20.1 \%$ in the United States (1). With high incidence, hypertension significantly influences the health in elderly people and the morbidity of this disease has been increasing over the past few decades. Although many advances in drug development and therapy have been achieved, thus far, the pathogenesis of hypertension has not been completely clarified.

Recent experimental evidence indicates that hypertension is predominantly a multifactorial disorder involving a complicated interaction between environmental influences and polygenetic defects. In particular, patients with familial aggregation hypertension display a strong trend in genetic predisposition. This raises the possibility that the products of several causal genes may work together in the development of hypertension, which contribute to a $30-50 \%$ variation in blood pressure among those hypertensive individuals $(2,3)$.

In this study, gene-chip was used to compare the gene expressions in second-order mesenteric arteries and kidneys between two rat models, the spontaneously hypertensive rat (SHR) and the Wistar-Kyoto (WKY) rat. Furthermore, real-time RT-PCR was used to confirm that FXYD5 was down-regulated in SHR in kidney and second-order mesenteric arteries. Northern blot results also suggested that the gene expression level was significantly different in the different stages of hypertension and different tissues. Therefore, these results could provide new theoretical evidence for the inherent mechanism of hypertension.

\section{Materials and methods}

Animals and cell line. Both WKY and SHR rats were obtained from the Shanghai Laboratory Animal Center. All rats were housed in a room with an ambient temperature of $21^{\circ} \mathrm{C}$, and 12-h, 12-h light/dark cycle. The animal experiments were carried out with the male rats at ages of 4-21 weeks, and approved by the Animal Research Committee of Wenzhou Medical College following the animal study guidelines of the National Institutes of Health, USA. Rat thoracic aortic smooth muscle cell line (CRL-1444) was purchased from the American Tissue Culture Collection, and was cultured in DMEM with 
10\% FBS (Invitrogen, USA). The renal tubular epithelial cell line of rat (NRK-52E) was purchased from Shanghai Institutes for Biological Sciences Cell Resource Center of Chinese Academy of Sciences, and was cultured in DMEM with 5\% FBS (Invitrogen).

Reagents. The TRIzol reagent was purchased from Invitrogen Corporation. The rat expression array (SBC-R-RC-100-13) was prepared by the Shanghai Biochip Company (Shanghai, China). The reverse transcription reagent was purchased from Fermentas. All the PCR reagents were provided commercially from Promega.

Blood pressure measurement. Intraperitoneal injection of butaylone $(50 \mathrm{mg} / \mathrm{kg}$ weight) was used to anesthetize the animals. The blood pressure was measured by the arterial caudilis. MedLab V 5.0 Bio-signal collect-processing system (Nanjing Medease Science and Technology Co., Ltd.) simultaneous recorded the pressure and pulse curve. The mean blood pressure was obtained after three measurements made on each animal.

RNA extraction and analysis. Total-RNA was extracted from the tissues using TRIzol reagent according to the manufacturer's instructions (Invitrogen). The quality of the RNA samples was assessed by electrophoresis showing distinct $28 \mathrm{~S}$ and $18 \mathrm{~S}$ ribosomal bands on a non-denaturing gel and by a densitometer showing the density ratio of $28 \mathrm{~S} / 18 \mathrm{~S}$ between 1.5-2.0. The purity of RNA was assessed by spectrophotometry (A260/A280 >1.8). Total-RNA of kidney and second-order mesenteric arteries from three rats was mixed by a ratio of 1:1 in each group. Subsequently, the cDNA was synthesized from the mixed total RNA by reverse transcription (RT) and labeled with fluorescent dyes. The SHR total-RNA was labeled with Cy3-dUTP while that of WKY was labeled with Cy5-dUTP. The labeled cDNA was purified using CyScribe GFX Purification kit (GE Healthcare Life Sciences, USA).

DNA chip hybridization. DNA chips (including 10,000 genes of rat, Shang Biochip Co., Ltd., Shanghai, China) and probes labeled with $\mathrm{Cy} 3$ or Cy 5 were denatured for $5 \mathrm{~min}$ at $95^{\circ} \mathrm{C}$. Then the probes were added onto DNA chips and sealed with a slide, and then hybridized at $42^{\circ} \mathrm{C}$ for $15-17 \mathrm{~h}$. DNA chips were scanned by GenePix 4100 (Axon Co.) (general scanning) and analyzed with GenePix 4.0 to obtain the intensity of two kinds of fluorescence, Cy3 intensity of SHR (13-weeks-old) and Cy5 intensity of WKY (13-weeks old). With a correcting value for the normalization coefficient, $\mathrm{Cy} 5 / \mathrm{Cy} 3$ ratio of all genes was calculated. A ratio of $>2.0$ or $<0.5$ was considered as significant. The ratio between 2.0-0.5 was not significant. Another criteria to judge the differential gene expression was that the Cy 3 and Cy 5 density must be $>200$ or $<800$ and simultaneous the ratio of $\mathrm{Cy} 5 / \mathrm{Cy} 3$ should be between 0.1-10.

Analysis of RNA by real-time PCR. RNA from kidney and second-order mesenteric arteries derived from 13-week-old male rats were mixed at a ratio of 1:1. A total of $1 \mu \mathrm{g}$ of RNA from each sample was reverse-transcribed using oligo(dt) primer and Moloney murine leukemia virus reverse transcriptase according to the protocol of the manufacturer (Fermentas).
For the real-time PCR, the first strand cDNA was synthesized following the protocol of Takara (Dalian, China) SYBR Premix Ex Taq. Relative gene expression quantity for FXYD5, with GAPDH as an internal reference gene, was carried out using the ABI PRISM 7000 sequence detection system (Applied Biosystems, Foster City, CA) in triplicates, based on the SYBRGreen method. The following primers were used for RT-PCR of targeted gene expression: for FXYD5, forward primer, 5'-CCAATGAGAACAGCCCCTTCT-3' and reverse primer, 5'-AGTGGCAGTGATGGCATGGACT-3'; for GAPDH, forward primer, 5'-TCCTGCACCACCAACTGCTTAG-3' and reverse primer, 5'-AGTGGCAGTGATGGCATGGACT-3'. The PCR reaction mixture consisted of $0.1 \mathrm{mmol} / \mathrm{l}$ of each primer, 1X SYBR Premix Ex Taq (perfect real-time) premix reagent (Takara), and $50 \mathrm{ng}$ cDNA to a final volume of $25 \mu \mathrm{l}$. The amplification parameters were as follows: initial one cycle of $2 \mathrm{~min}$ at $50^{\circ} \mathrm{C}$, then $95^{\circ} \mathrm{C}$ for $2 \mathrm{~min}$, followed by 40 cycles of $15 \mathrm{sec}$ at $95^{\circ} \mathrm{C}$ and $1 \mathrm{~min}$ at $59^{\circ} \mathrm{C}$. All reactions were performed three times. Real-time data were analyzed by using ABI PRISM 7000 SDS version 1.1.

Probe synthesis and Northern blotting. The vector of Bluescript II SK (+/-) (Stratagene) containing the PCR products of FXYD5 was constructed. Rat FXYD5 cRNA was labeled with digoxigenin, using the plasmid method according to the manufacturer's instructions (DIG RNA labeling kit, Roche Diagnostics, Germany). Before use, the labeled probe was purified to remove unincorporated digoxigenin-labeled nucleotides. Total-RNA obtained at each stage was separated using a $1.2 \%(\mathrm{w} / \mathrm{v})$ formaldehyde agarose gel and transferred to a nylon membrane (Hybond $\mathrm{N}^{+}$, Amersham) and crosslinked by UV light. The membrane was pre-hybridizated with hybridization solution at $68^{\circ} \mathrm{C}$ for $2 \mathrm{~h}$, and then hybridized with a digoxigenin-labeled probe at $68^{\circ} \mathrm{C}$ for $12-16 \mathrm{~h}$. Blots were developed with CDP-star (KPL). For quantitative analysis, the Quantity One (Bio-Rad) software was used to measure densities of developed bands. The intensity of bands for FXYD5 was normalized by that of stained ribosomal RNA bands following staining with ethidium bromide.

Preparation and transfection of siRNAs. The siRNAs targeting FXYD5 gene of rat were designed and synthesized by GenePharma (China) (the sequences are shown in Table I). The siRNAs were transfected to CRL-1444 cells using Lipofectamine $^{\mathrm{TM}} 2000$ (Invitrogen, USA) as described in the manufacturer's instructions. At $48 \mathrm{~h}$ after transfection, RNA was extracted from the cells. The efficiency of RNA interference (RNAi) was determined by real-time RT-PCR.

Construction and transfection of eukaryotic expression vector of pcDNA3.1(+)-FXYD5. The pBluescript II KS (+/-) vector which contained full-length FXYD5 cDNA were amplified by PCR. The forward primer was 5'-CGGGAATTCAGAC CTTGGGCTCGGACA-3'. The reverse primer was 5'-CGC TATCCAGAGGCAGGGGTGGTGAAC-3' (underlined in order were $E c o$ RI and $E c o$ RV restriction sites). The amplification parameters were as follows: the cDNA products were amplified for a total of 30 cycles of PCR, the first denaturation for $5 \mathrm{~min}$ at $94^{\circ} \mathrm{C}$, with each cycle consisting of denaturation for $30 \mathrm{~min}$ at $94^{\circ} \mathrm{C}$, annealing for $30 \mathrm{~min}$ at $57^{\circ} \mathrm{C}$ and extension 
Table I. siRNA sequences.

\begin{tabular}{lll}
\hline Name & & \multicolumn{1}{c}{ Sequence } \\
\hline siRNA-1 & Sense & 5'-GAGUUCUGUGACUACUCAUTT-3' \\
& Antisense & 5'-AUGAGUAGUCACAGAACUCTG-3' \\
siRNA-2 & Sense & 5'-CGAAAUGGCCACUGCGAAUTT-3' \\
& Antisense & 5'-AUUCGCAGUGGCCAUUUCGTT-3' \\
siRNA-con & Sense & 5'-UUCUCCGAACGUGUCACGUTT-3' \\
& Antisense & 5'-ACGUGACACGUUCGGAGAATT-3'
\end{tabular}

for $1 \mathrm{~min}$ at $72^{\circ} \mathrm{C}$ respectively and the final extension for $10 \mathrm{~min}$ at $72^{\circ} \mathrm{C}$. Then, the PCR product was recycled and cloned into a pcDNA3.1(+) plasmid. The recombinant plasmid was confirmed by PCR, double enzyme digestion analysis and DNA sequencing. The recombinant plasmid pcDNA3.1(+)-FXYD5 was transfected into NRK-52E cells using Lipofectamine ${ }^{\mathrm{TM}}$ 2000 (Invitrogen) as described in the company's instructions. After $48 \mathrm{~h}$, the RNA was extracted from the cells. The mRNA of FXYD5 was detected by real-time RT-PCR.

Real-time quantitative RT-PCR. Real-time quantitative RT-PCR was carried out as previously described in 4 cell groups named siRNA-1, siRNA-2, siRNA-con and blank in which cells were left untreated. The cells were respectively transfected with siRNA-1, siRNA-2 and siRNA-con which has no homology with the mammalian gene. Cells were transfected with pcDNA3.1(+)-FXYD5 as the experimental group (PF), transfected with pcDNA3.1(+) as negative control group (NC) and with no treatment as the blank control group (BC). Total-RNA was extracted from the cells using TRIzol reagent according to the manufacturer's instructions (Invitrogen) and treated by DNase I to avoid perturbation by genomic DNA. The cDNA was synthesized from $100 \mathrm{ng}$ of total-RNA by reverse transcription (RT) at $48^{\circ} \mathrm{C}$ for $30 \mathrm{~min}$ by random hexamers. The cDNA products were amplified for a total of 40 cycles of $\mathrm{PCR}$, the first denaturation for $10 \mathrm{~min}$ at $95^{\circ} \mathrm{C}$, with each cycle consisting of denaturation for $12 \mathrm{~min}$ at $92^{\circ} \mathrm{C}$, annealing and extension for $1 \mathrm{~min}$ at $60^{\circ} \mathrm{C}$ respectively. All reactions were performed in triplicates and the results were normalized by GAPDH.

Cell proliferation and migration. Cell proliferation was measured by a cell counting kit-8 (CCK-8) assay purchased from Dojindo Laboratories (Kumamoto, Japan). CRL-1444 cells and NRK-52E cells were suspended at a final concentration of 5,000 cells/well and cultured in 96-well flat bottom microplates. At $48 \mathrm{~h}$ after transfection of siRNAs and recombinant plasmid pcDNA3.1(+)-FXYD5, $10 \mu$ l CCK-8 was added to each well containing $90 \mu \mathrm{l}$ of culture medium and the plate was incubated for $1 \mathrm{~h}$ at $37^{\circ} \mathrm{C}$. Viable cells were counted by absorbance measurements at $450 \mathrm{~nm}$ using an automated microplate reader ELx800 (BioTek). Cell vitality (\%) was calculated as the ratio of $\left(\mathrm{A}_{\text {transfection group }}-\mathrm{A}_{\text {control }}\right) /\left(\mathrm{A}_{\text {blank }}-\mathrm{A}_{\text {control }}\right)$ $\mathrm{x} 100$. The monolayer wound healing assay was used to measure cell migration. Cells were grown to full confluence in 6-well plates then incubated overnight in DMEM. The cell cultures were scratched with a $1,000 \mu l$ sterile pipette tip and exten- sively washed with PBS to remove detached cells and debris. Then the cells were incubated overnight in DMEM with 5\% FBS. Finally, the cells were washed by PBS and fixed with $4 \%$ formaldehyde followed by $0.1 \%$ Triton X-100 and stained by hematoxylin. Three randomly selected visions were obtained by the microscope and the distance from the farthest cell to the beginning was measured by the Image-Pro Plus software. All experiments were performed in triplicates.

Measurement of $\mathrm{Na}^{+}-\mathrm{K}^{+}$-ATPase activity. $\mathrm{Na}^{+}-\mathrm{K}^{+}$-ATPase activity was measured by the $\mathrm{Na}^{+}-\mathrm{K}^{+}$-ATPase micro test kit following Jiancheng Institute of Biotechnology (Nanjing, China) protocols. $\mathrm{Na}^{+}-\mathrm{K}^{+}$-ATPase can catalyze ATP to generate ADP and inorganic phosphorus. The amount measurement of inorganic phosphorus can be used to determine the $\mathrm{Na}^{+}-\mathrm{K}^{+}-$ ATPase activity. After transfection the cells were washed twice with cold $0.9 \%$ saline solution and then suspended in $0.2 \mathrm{ml} 0.9 \%$ saline solution, and disrupted by ultrasonication. The concentration of protein was determined by bicinchoninic acid assay (Pierce, USA).The enzymatic reaction was reacted at $37^{\circ} \mathrm{C}$ for $10 \mathrm{~min}$. The production inorganic phosphorus and $0.02 \mathrm{mmol} / 1$ standard phosphate solution as control was measured by a spectrophotometer (Xingmao 721, Shanghai, China, excitation wavelength $636 \mathrm{~nm})$.

Statistical analysis. All quantitative data were analyzed using SPSS11.5 software. Data are presented as means \pm SE. Significant differences between groups were assessed by independent-samples Student's t-test and Dunnett's t-test for multiple comparisons. $\mathrm{P}<0.05$ indicates that the difference is significant.

\section{Results}

Microarray demonstration of gene changes in aging SHR. The genetic heterogeneity was determined in SHR and WKY rats by comparing the expression of 10,000 genes. Thirtyeight genes of interest were selected including genes relevant to cell signal transduction, cell cycle, enzymes that directly participate in the metabolism (MET) and nuclear factors. Of the 38 genes, 19 were up-regulated and the other 19 genes were down-regulated as shown in Tables II and III.

Determination of FXYD5 gene expression by real-time PCR and Northern blotting. As determined by real-time PCR, the expression of FXYD5 in the SHR group was down-regulated $(14.8 \pm 0.6)$ more than that in the WKY group $(\mathrm{P}<0.01)$ (Fig. 1). 
Table II. Down-regulated genes in 13-week-old rats identified by gene array technology.

\begin{tabular}{|c|c|c|}
\hline GenBank number & Gene name & Fold down-regulated \\
\hline NM_139192 & Stearoyl-coenzyme A desaturase 1 & 21.00 \\
\hline U05341 & $\mathrm{p} 55 \mathrm{CDC}$ & 2.17 \\
\hline NM_021909 & FXYD domain-containing ion transport regulator 5 & 2.33 \\
\hline XM_131732 & Similar to hypothetical protein DJ159A19.3 & 2.21 \\
\hline NM_012797 & Inhibitor of DNA binding 1, helix-loop-helixprotein & 2.01 \\
\hline NM_053907 & Deoxyribonuclease I-like 3 & 3.66 \\
\hline M18854 & Rat T-cell receptor active $\beta$-chain C-region mRNA & 15.63 \\
\hline NM_017014 & Glutathione-S-transferase, $\mu$ type 2 & 3.22 \\
\hline NM_131902 & Cyclin dependent kinase inhibitor $2 \mathrm{C}$ & 2.82 \\
\hline L22653 & Rat anti-acetylcholine receptor antibody gene, $\kappa$-chain & 10.59 \\
\hline NM_017165 & Glutathione peroxidase 4 & 2.05 \\
\hline AB028626 & mRNA for R-ras GTPase activating protein & 2.00 \\
\hline NM_016698 & Ring finger protein 10 & 14.04 \\
\hline AF343581 & RanBp21 mRNA & 2.13 \\
\hline NM_019292 & Carbonic anhydrase 3 & 13.37 \\
\hline ВC022167 & Nuclear protein 95 & 2.32 \\
\hline NM_013191 & S100 calcium-binding protein, $\beta$ & 2.38 \\
\hline NM_017332 & Fatty acid synthase & 2.38 \\
\hline XM_131329 & Similar to mitogen-activated protein kinase kinase kinase 7 & 5.85 \\
\hline
\end{tabular}

Table III. Up-regulated genes in 13-week-old rats identified by gene array technology.

\begin{tabular}{|c|c|c|}
\hline GenBank number & Gene name & Fold up-regulated \\
\hline U40652 & Tyrosine phosphatase-like protein IA-2a mRNA & 3.812 \\
\hline NM_130744 & Stellate cell activation associated protein & 3.036 \\
\hline NM_017116 & Calpain 2 & 3.029 \\
\hline NM_031822 & Nuclear receptor coactivator 2 & 3.022 \\
\hline AY090783 & Platelet-derived growth factor receptor $\beta$ & 2.596 \\
\hline NM_024369 & Follistatin-related protein precursor & 2.399 \\
\hline AF139830 & Insulin-like growth factor binding protein 5 & 2.535 \\
\hline NM_053583 & Olf-1/EBF associated Zn finger protein Roaz & 2.35 \\
\hline NM_030856 & Neuronal leucine-rich repeat protein-3 & 2.246 \\
\hline X72859 & mRNA for tropomyosin isoform 6 & 2.227 \\
\hline NM_053582 & Glucocorticoid-inducible protein & 2.225 \\
\hline NM_021587 & Transforming growth factor- $\beta$ & 2.157 \\
\hline NM_022948 & Tricarboxylate carrier-like protein & 2.151 \\
\hline NM_017064 & Signal transducer and activator of transcription $5 \mathrm{a}$ & 2.135 \\
\hline Z75029 & hsp70.2 mRNA for heat shock protein 70 & 2.106 \\
\hline NM_030990 & Proteolipid protein & 2.09 \\
\hline U22372 & Vascular endothelial growth factor gene & 2.076 \\
\hline NM_053442 & Solute carrier family 7 & 2.027 \\
\hline XM_122409 & Mus musculus cofilin 2 & 2.02 \\
\hline
\end{tabular}

Further analysis showed that FXYD5 expression was more abundant in the lung and mesenteric arteries, but less adundant in the brain, kidney and heart of 13-week SHR. No visible band was found in the liver specimen (Fig. 2). There was a characteristic difference in tissue distribution of FXYD5 among SHR animals of different ages.
Northern blotting results showed that FXYD5 was differentially expressed in SHR and WKY kidneys at 4, 8, 13 and 21 weeks (Fig. 3). Comparison between either 4- or 8-week WKY and SHR rats revealed that there was no difference between WKY and SHR kidneys. But in the 13-week group, the mRNA level of FXYD5 in SHR rats was much lower than 


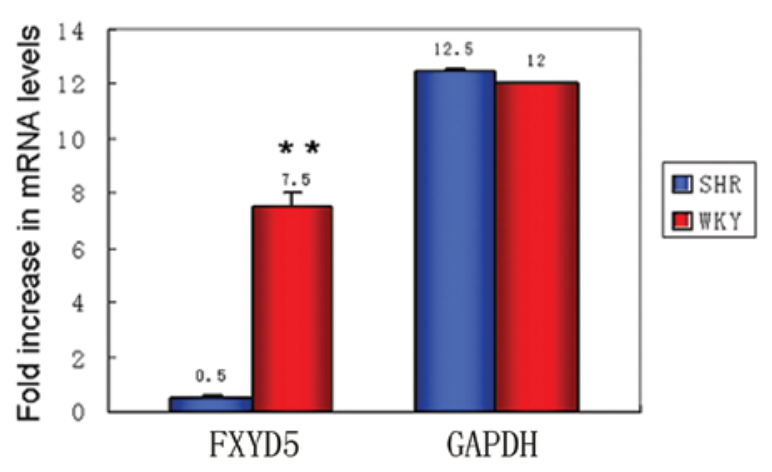

Figure 1. Real-time quantitative RT-PCR analysis of FXYD5 mRNA in SHR and WKY rats. Total-RNA extracted from the kidney and mesenteric arterial tissues (1:1) was analyzed by real-time RT-PCR. Data represent means $\pm \mathrm{SE}$, $\mathrm{n}=3 .^{* *} \mathrm{P}<0.01$.
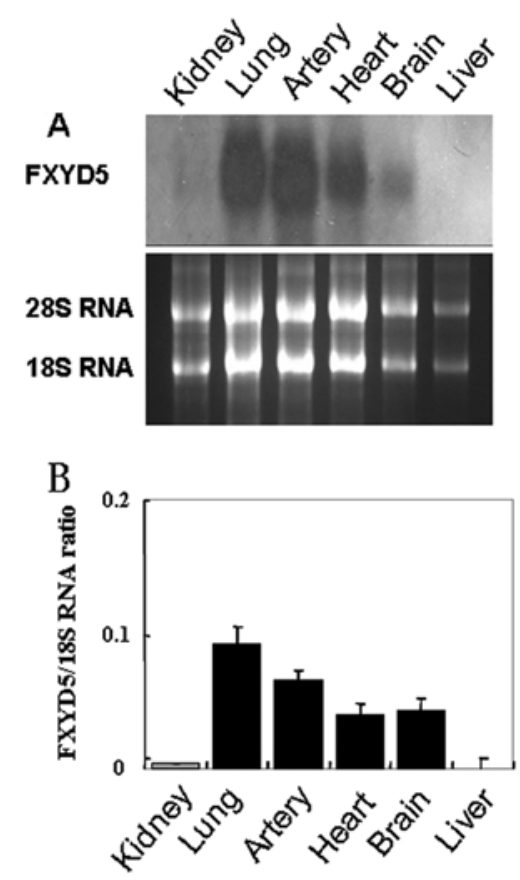

Figure 2. Northern blotting for FXYD5 mRNA in different tissues or organs of 13-week-old SHR rats. (A) Representative Northern blotting bands (upper panel) for FXYD5 using RNA samples from the kidney, lung, mesenteric arteries, heart, brain and liver tissues. rRNA bands at 28S and 18S shown in the lower panel. (B) The densitometry of FXYD5 mRNA band against rRNA band. Each bar represents mean $\pm \mathrm{SE}, \mathrm{n}=3$.

that in WKY $(\mathrm{P}<0.01)$. The 21-week rat group also had this difference $(\mathrm{P}<0.05)$. On the other hand, the peak expression level of FXYD5 mRNA in the kidney was found at 13 weeks in the WKY group, and then it decreased gradually. In the SHR group, the peak expression was observed at 8 weeks. In WKY or SHR rats, peak expression occurred at a different age. The peak of 13-week WKY was obviously higher than that of 8-week SHR (Fig. 4). Thus, the FXYD5 gene expression was significantly suppressed in SHR with hypertension.

Construction of the eukaryotic expression vectorpcDNA3.1(+)FXYD5. The FXYD5 gene was successively cloned into the eukaryotic expression vector that was identified by colony PCR, double enzyme digestion analysis and sequencing.

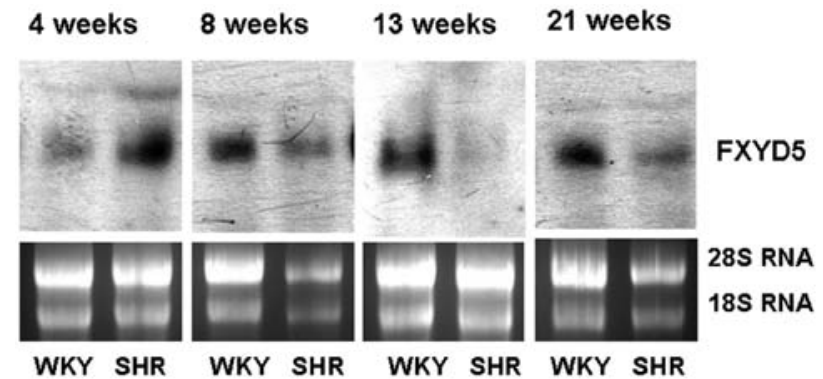

Figure 3. Northern blotting for FXYD5 mRNA in SHR and WKY kidneys. Total-RNA (20 $\mu \mathrm{g} /$ lane) from kidney was resolved in agarose gels, transferred onto membranes and then hybridized with rat dig-labeled-FXYD5 cRNA fragment (upper panels). RNA integrity was confirmed by staining rRNA bands (lower panels).

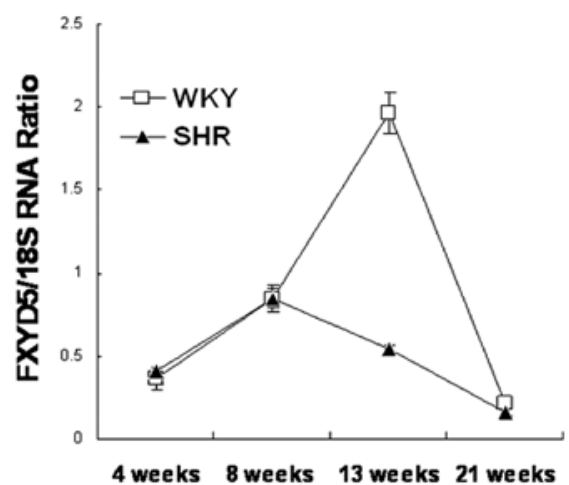

Figure 4. Relative expression of FXYD5 mRNA at different weeks (4, 8, 13, 21-week) in the rats kidneys. The expression of FXYD5 in kidneys was determined by real-time PCR as described in the Materials and methods.

Determination of the $m R N A$ expression of FXYD5 by realtime PCR after transfection. The results of the interference efficiency of siRNAs showed that the expression level of FXYD5 mRNA was suppressed by $86.71 \%$ (siRNA-1, $\mathrm{P}<0.01$ ) and $90.17 \%$ (siRNA-2, $\mathrm{P}<0.01$ ) as compared to the control. No significant difference was observed between siRNAcon and blank $(\mathrm{P}>0.05)$ (Fig. 5A). After the transfection of pcDNA3.1(+)-FXYD5, the expression levels of FXYD5 in the $\mathrm{PF}$ group was 9.645-fold higher $(\mathrm{P}<0.05)$ as compared to the $\mathrm{BC}$ group and not significantly different between the $\mathrm{NC}$ and $\mathrm{BC}$ groups $(\mathrm{P}>0.05)$ (Fig. 5B).

Effects on cell proliferation and migration after FXYD5 expression. The study of the effect of FXYD5 inhibition on the cellular proliferation did not show any significant differences among the 4 groups (Table IV). In NRK-52E cells, the cell vitality in PF group was higher than in the NC group $(97.400 \pm 4.285 \%$ and $84.820 \pm 3.272 \%)(\mathrm{P}<0.05)$, but not significantly different from the $\mathrm{BC}$ group $(\mathrm{P}>0.05)$ (Fig. 6).

The results of the cell migration assay demonstrated that the migratory distance was $188.098 \pm 9.900 \mu \mathrm{m}$ for the siRNA-1 group $(\mathrm{P}<0.01), 180.247 \pm 25.497 \mu \mathrm{m}$ for the siRNA-2 group $(\mathrm{P}<0.01), 245.690 \pm 24.438 \mu \mathrm{m}$ for the siRNA-con group ( $>0.05$ ) and 250.866 $\pm 21.887 \mu \mathrm{m}$ for the blank group (Fig. 7). Significant reduction of the migratory ability was observed in both siRNA-1 and siRNA-2 groups. No significant difference was observed in the siRNA-con group. The results show that 

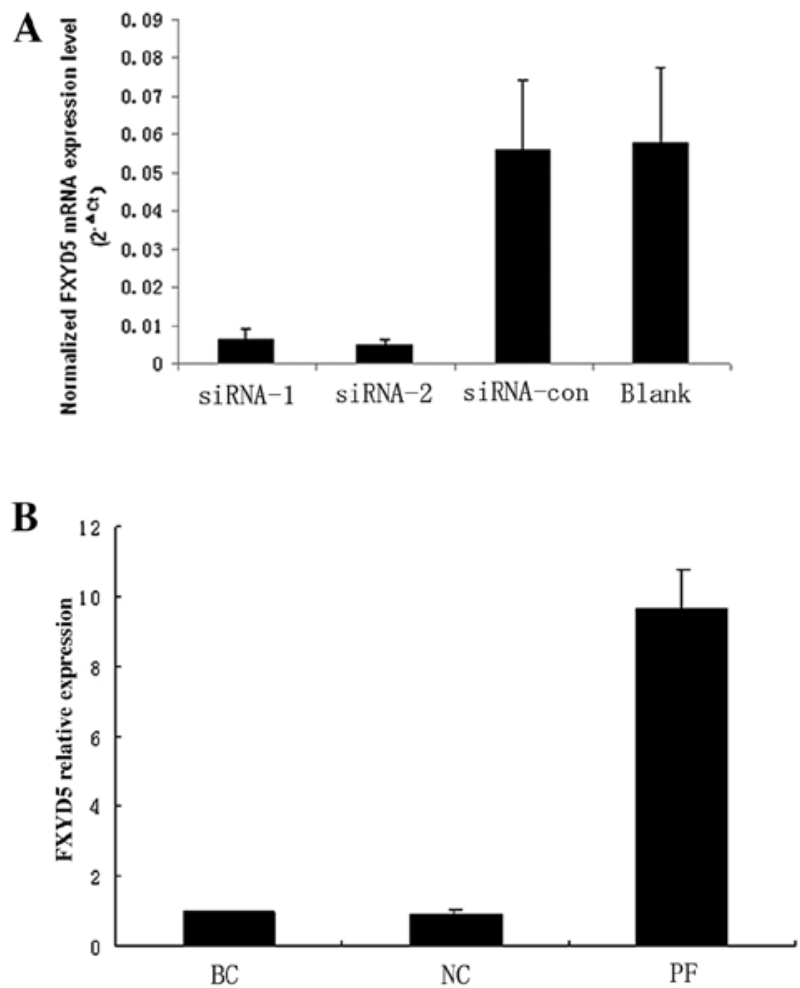

Figure 5. The level of FXYD5 mRNA expression in cell lines. (A) The level of FXYD5 mRNA expression among four groups after the interference of siRNAs. (B) The level of FXYD5 mRNA expression among three groups after transfection of eukaryotic expression vector. PF, cells transfected with pcDNA3.1(+)-FXYD5; NC, transfected with pcDNA3.1(+) as the negative control group (NC); and $\mathrm{BC}$, the blank control group.

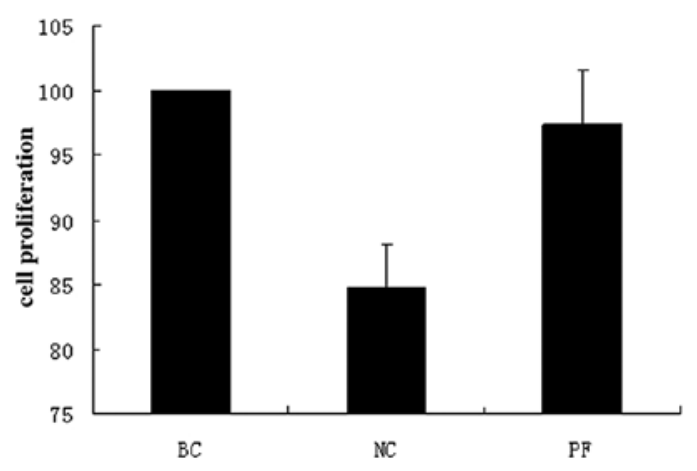

Figure 6. Cell proliferation of each group $48 \mathrm{~h}$ after transfection. The cell proliferation of the $\mathrm{PF}$ group was higher than that of the $\mathrm{NC}$ group $(\mathrm{P}<0.05)$ but not significant different from the $\mathrm{BC}$ group $(\mathrm{P}>0.05)$. $\mathrm{PF}$, cells transfected with pcDNA3.1(+)-FXYD5; NC, transfected with pcDNA3.1(+) as the negative control group (NC); and $\mathrm{BC}$, the blank control group.

silenced FXYD5 mRNA expression might induce the inhibition of migration of vascular smooth muscle cells.

$\mathrm{Na}^{+}-\mathrm{K}^{+}$-ATPase activity and FXYD5 inhibition. The $\mathrm{Na}^{+}-\mathrm{K}^{+}-$ ATPase activity was determined to be $2.894 \pm 0.170 \mathrm{U} / \mathrm{mgprot}$ for the siRNA-1 group $(\mathrm{P}<0.01), 2.944 \pm 0.060 \mathrm{U} / \mathrm{mgprot}$ for the siRNA-2 group $(\mathrm{P}<0.01), 3.587 \pm 0.064 \mathrm{U} / \mathrm{mgprot}$ for the siRNA-con $(\mathrm{P}>0.05)$ and $4.006 \pm 0.048 \mathrm{U} / \mathrm{mgprot}$ for the blank group (Fig. 8A). In NRK-52E cells, the $\mathrm{Na}^{+}-\mathrm{K}^{+}$-ATPase activity was $5.466 \pm 0.306$ ( $\mathrm{PF}$ group, $\mathrm{P}<0.05$ ), $4.301 \pm 0.148$ (NC group, $\mathrm{P}>0.05$ ) and 4.026 \pm 0.213 (BC group) (Fig. 8B).
Table IV. Effect of the cellular proliferation in the four groups.

\begin{tabular}{lcc}
\hline Groups & OD (A450) & P-value $^{\mathrm{a}}$ \\
\hline siRNA-1 & $1.040 \pm 0.141$ & 0.068 \\
siRNA-2 & $1.097 \pm 0.206$ & 0.377 \\
siRNA-con & $1.062 \pm 0.111$ & 0.153 \\
Blank & $1.184 \pm 0.152$ &
\end{tabular}

No significant difference was observed among four groups ( $\left.{ }^{\mathrm{a}} \mathrm{P}>0.05\right)$.
A

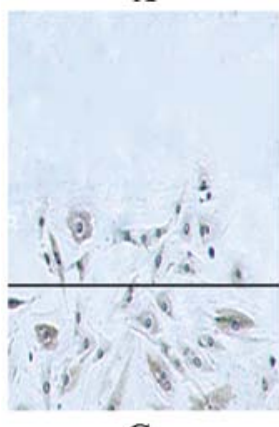

C

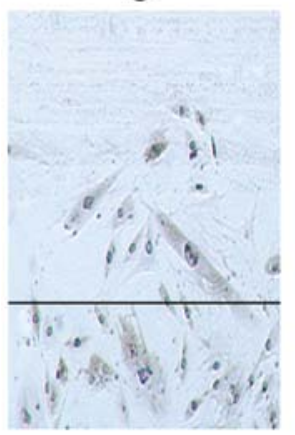

B

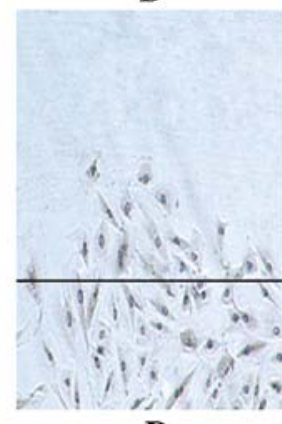

D

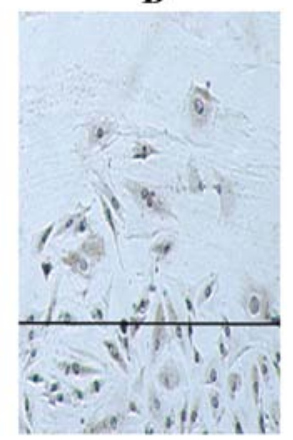

Figure 7. Observation of the cell migratory ability. (A) siRNA-1, (B) siRNA-2, (C) siRNA-con and (D) blank group (x40).

The results show that the silenced FXYD5 mRNA expression may induce the $\mathrm{Na}^{+}-\mathrm{K}^{+}$-ATPase activity positive change.

\section{Discussion}

SHR was first described by Okamoto and Aoki (4), who had undertaken a selective brother-sister inbreeding of WKY rats with an outbreed WKY male and a female rat with slightly elevated blood pressure. SHR is commonly used as an animal model to explore the pathogenesis and management of essential hypertension in humans because of its common origin and complete control over environmental influences. It mimcs the essential hypertension in humans in that the SHR develops spontaneous hypertension without any treatment and it also exhibits similar end-organ damage phenotypes to that in human essential hypertension $(5,6)$.

Human essential hypertension is a classic example of a complex, multifarious, polygenic disease. One of the environmental contributing factors is aging. It is the dominant process altering vascular stiffness, wave reflections, and pulse pressure. Thus, the morbidity rate of hypertension could 

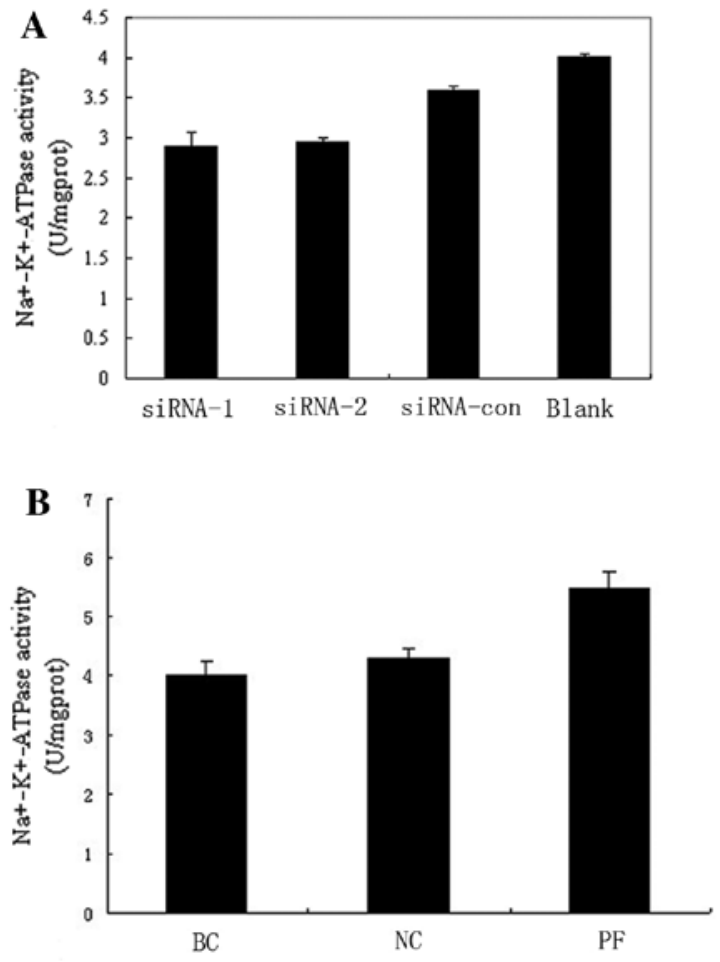

Figure 8. Determination of $\mathrm{Na}^{+}-\mathrm{K}^{+}$-ATPase activity. (A) The effect of the cell membrane $\mathrm{Na}^{+}-\mathrm{K}^{+}$-ATPase activity among four groups. The experimental groups were compared to the blank by means of the Dunnett's t-test. Values are the means \pm SD. The activity of cell membrane $\mathrm{Na}^{+}-\mathrm{K}^{+}$-ATPase in the siRNA-1 and siRNA-2 transfected groups was lower than in the blank control group $(\mathrm{P}<0.01)$. No significant difference was found between the siRNA-con transfected group and the blank control group ( $\mathrm{P}>0.05)$. (B) The effect of the cell membrane $\mathrm{Na}^{+}-\mathrm{K}^{+}$-ATPase activity among three groups. The cell membrane $\mathrm{Na}^{+}-\mathrm{K}^{+}$-ATPase activity of the PF group was higher than the $\mathrm{BC}$ group and the $\mathrm{NC}$ group $(\mathrm{P}<0.05)$.

increase with aging. In addition to the environmental factors, endogenous factors influence blood pressure while aging $(7,8)$. Some researchers had been using DNA microarray analysis to explore differentially expressed genes in kidneys and vascular smooth muscle cells (VSMCs) between different stages of SHR and WKY. Our study revealed that 19 genes were down-regulated and might be related to essential hypertension. These include genes relevant to cell signal transduction, cell cycle, enzyme that directly participate in metabolism (MET), calcium binding protein, and nuclear factors according to their effectiveness and functions. Significant differences have been reported in the expression of certain genes involved in lipid metabolism (9). Microarray analysis of VSMCs derived from young SHR and identified several enzymes, adhesion molecules and cytokines, which were independent of hypertension and possibly associated with genetic abnormalities (10). It was found that certain genes involved in lipid metabolism were also involved in SHR, however, the level of the fatty acid synthase expression was down-regulated in SHR. It has also been reported that carbonate dehydratase 3 and S100 calcium combining protein were down-regulated in the adrenal of SHR (11). Seubert et al (12) examined the renal gene expression profiles between SHR and WKY at a prehypertensive stage (3-weeksold) and hypertensive stage (9-weeks-old). Twenty-two genes were differentially expressed between SHR and WKY at 3-weeks-old, and 104 genes were differentially expressed at 9-weeks-old.

Many factors could influence the microarray results, and it is just a qualitative test or a semi-quantitative analysis. For the purpose of excluding false positivity in microarray, realtime quantity RT-PCR was used to verify the genes that are down-regulated in SHR. It was found that the FXYD5 was significantly down-regulated in second-order mesenteric arteries and kidneys of SHR rats. FXYD5 (related to ion channel, dysadherin) is a member of the FXYD family of single span type I membrane proteins which are characterized by an FXYD motif, two conserved glycine and a serine residue. FXYD5 has some differences on its structures: a long extracellular domain $>140$ amino acids and a short intracellular C-terminal segment of only 15 amino acids.

Each member of the FXYD proteins family showed a tissue-specific distribution. FXYD5 is an epithelial protein that is specifically expressed in the kidney cortex, intestinal duodenum, spleen and lung (13). On our data FXYD5 mRNA was much more abundant in the lung and second-order mesenteric arteries than in the kidney or other tissues such as the heart and brain. Other studies have reported that the levels of FXYD 5 mRNA expression were 5-fold higher in lung than in small or large intestine, heart, brain, liver or kidney in mice (14). Some in-depth studies on kidney distribution found that FXYD5 was localized at the basolateral membrane of the connecting tubule, the collecting tubule, the intercalated cells of the collecting duct, colorectal carcinoma, thyroid carcinoma and so on (16). In the present study, we found that the level of FXYD5 gene expression was different in the kidney in SHR at different ages. Therefore, FXYD5 may play an important role in physiological and pathological processes.

Subsequent experiments have also clarified that the primary event in essential hypertension is the enhanced tubular sodium reabsorption by the increased activity and expression of $\mathrm{Na}^{+}-\mathrm{K}^{+}$-ATPase. Evidence suggests that FXYD1-4 and FXYD7 proteins could also regulate $\mathrm{Na}^{+}-\mathrm{K}^{+}$-ATPase. $\mathrm{Na}^{+}-\mathrm{K}^{+}$-ATPase (phospholemman), FXYD2 $\left(\gamma\right.$ subunit of $\mathrm{Na}^{+}-\mathrm{K}^{+}$-ATPase), FXYD3 (Mat-8), FXYD4 (CHIF) and FXYD7-associated with $\mathrm{Na}^{+}-\mathrm{K}^{+}$-ATPase modulate its transport properties e.g. its $\mathrm{Na}^{+}$and/or its $\mathrm{K}^{+}$affinity in a distinctive way (17). Recently Lubarski et al (13) revealed that the FXYD5 also regulated $\mathrm{Na}^{+}$and $\mathrm{K}^{+}$reabsorption by regulating the $\mathrm{Na}^{+}-\mathrm{K}^{+}$-ATPase . Co-expressing FXYD5 with the $\alpha 1$ and $\beta 1$ subunits of the $\mathrm{Na}^{+}-\mathrm{K}^{+}$-ATPase in Xenopus oocytes elicited a more than 2-fold increase in pump activity. Karlish et al revealed that the interaction of FXYD5 with $\mathrm{Na}^{+}-\mathrm{K}^{+}$-ATPase is similar to that with FXYD2 mainly because of the transmembrane domains in FXYD5 (18). FXYD5 also down-regulates E-cadherin and promotes metastasis, but this function might not be mediated by the transmembrane domain of FXYD5 $(13,18)$. In fact, FXYD5 is abundant in lung, which also implies the important role of FXYD5 in this tissue.

Furthermore, we silenced the FXYD5 mRNA expression in VSMCs by RNAi to alter the state of SHR in vivo. It was found that the low level expression of FXYD5 mRNA could result in reduction of $\mathrm{Na}^{+}-\mathrm{K}^{+}$-ATPase activity on cell membrane. Meanwhile, when the level of FXYD5 mRNA 
expression was increased in renal tubular epithelial cells by the eukaryotic expression vector pcDNA3.1(+)-FXYD5, the high level of FXYD5 mRNA expression could enhance $\mathrm{Na}^{+}-\mathrm{K}^{+}$-ATPase activity on the cell membrane. Therefore, hypertension is highly correlated with $\mathrm{Na}^{+}-\mathrm{K}^{+}$-ATPase activity. FXYD5 may play an important role in the formation of hypertension through influencing $\mathrm{Na}^{+}-\mathrm{K}^{+}$-ATPase activity. Besides, inhibition of the expression of FXYD5 has no impact on the proliferation of VSMCs, but increasing expression of FXYD5 could enhance the proliferation of renal tubular epithelial cells. FXYD5 may influence the $\mathrm{Na}^{+}-\mathrm{K}^{+}$-ATPase activity on the cell membrane that induces related changes of physiological behavior of the cells, such as membrane potential, intracellular ion concentration changes. Some experiments had also confirmed that abnormal sodium pump could cause cell proliferation and apoptosis $(19,20)$. Inhibiting the expression of FXYD5 decreased the migration ability of VSMCs. This indicates that FXYD5 has anti-adhesion effect and may play a compensatory role in the aggressive-phase of hypertensive disease through remodeling of blood vessels. Therefore, FXYD5 may not simply play a role in the pathogenesis of hypertension. Compared to the primary cells, cell lines have some limitations. It has been established that, in either spontaneous or gene (including SV-40 large $\mathrm{T}$ antigen and HPV 18 E6/E7) transduced cell lines, only some of phenotypic characteristics of these cells are maintained. As the proteins encoded by viruses disrupt many cellular pathways, the transformed cells obtained are not normal cells whose phenotype and karyotype tend to be changed. They would be genetically unstable, including polynucleation, and loss and gaining whole or partial chromosomes. The life cycle of primary cells is limited. In a limited life cycle, the genotype and phenotype of cell populations is maintained constant.

Taken together, these findings support the genetic mechanisms of FXYD5 during the progress of essential hypertension. A characterization of the distribution of FXYD5 and its relationship with $\mathrm{Na}^{+}-\mathrm{K}^{+}$-ATPase may help better understand its role in physiological and pathophysiological conditions, such as essential hypertension.

\section{Acknowledgements}

This study was supported by the Wenzhou Nature Science Foundation (Y20090002) and the Ministry of Health of the People's Republic of China Science Foundation (wkj2008-2-031).

\section{References}

1. Joffres MR, Hamet P, MacLean DR, L'italien GJ and Fodor G: Distribution of blood pressure and hypertension in Canada and the United States. Am J Hypertens 14: 1099-1105, 2001.
2. Rice T, Vogler GP, Perusse L, Bouchard C and Rao DC: Cardiovascular risk factors in a French Canadian population: resolution of genetic and familial environmental effects on blood pressure using twins, adoptees, and extensive information on environmental correlates. Genet Epidemiol 6: 571-588, 1989.

3. Biron P, Mongeau JG and Bertrand D: Familial aggregation of blood pressure in 558 adopted children. Can Med Assoc J 115: 773-774, 1976

4. Okamoto K and Aoki K: Development of a strain of spontaneously hypertensive rats. Jpn Circ J 27: 282-293, 1963.

5. McBride MW, Charchar FJ, Graham D, Miller WH, Strahorn P, Carr FJ and Dominiczak AF: Functional genomics in rodent models of hypertension. J Physiol 554: 56-63, 2004.

6. Mueller PW, Hall WD, Caudill SP, MacNeil ML and Arepally A: An in-depth examination of the excretion of albumin and other sensitive markers of renal damage in mild hypertension. Am J Hypertens 8: 1072-1082, 1995.

7. Franklin SS, Larson MG, Khan SA, Wong ND, Leip EP, Kannel WB and Levy D: Does the relation of blood pressure to coronary heart disease risk change with aging? The Framingham Heart Study. Circulation 103: 1245-1249, 2001.

8. Safar ME, Levy BI and Struijker-Boudier H: Current perspectives on arterial stiffness and pulse pressure in hypertension and cardiovascular diseases. Circulation 107: 2864-2869, 2003.

9. Koo JR and Vaziri ND: Effects of diabetes, insulin and antioxidants on NO synthase abundance and NO interaction with reactive oxygen species. Kidney Int 63: 195-201, 2003.

10. Hu WY, Fukuda N and Kanmatsuse K: Growth characteristics, angiotensin II generation, and microarray-determined gene expression in vascular smooth muscle cells from young spontaneously hypertensive rats. J Hypertens 20: 1323-1333, 2002.

11. Friese RS, Mahboubi P, Mahapatra NR, Mahata SK, Schork NJ, Schmid-Schonbein GW and O'Connor DT: Common genetic mechanisms of blood pressure elevation in two independent rodent models of human essential hypertension. Am J Hypertens 18: 633-652, 2005.

12. Seubert JM, Xu F, Graves JP, Collin JB, Sieber SO, Paules RS, Kroetz DL and Zeldin DC: Differential renal gene expression in prehypertensive and hypertensive spontaneously hypertensive rats. Am J Physiol Renal Physiol 289: F552-F561, 2005.

13. Lubarski I, Pihakaski-Maunsbach K, Karlish SJ, Maunsbach AB and Garty $\mathrm{H}$ : Interaction with the $\mathrm{Na}, \mathrm{K}$-ATPase and tissue distribution of FXYD5 (related to ion channel). J Biol Chem 280: 37717-37724, 2005.

14. Aoki S, Shimamura T, Shibata T, Nakanishi Y, Moriya Y, Sato Y, Kitajima M, Sakamoto M and Hirohashi S: Prognostic significance of dysadherin expression in advanced colorectal carcinoma. Br J Cancer 88: 726-732, 2003.

15. Tamura M, Ohta Y, Tsunezuka Y, Matsumoto I, Kawakami K, Oda $M$ and Watanabe G: Prognostic significance of dysadherin expression in patients with non-small cell lung cancer. J Thorac Cardiovasc Surg 130: 740-745, 2005.

16. Sato H, Ino Y, Miura A, Abe Y, Sakai H, Ito K, Hirohashi S: Dysadherin: expression and clinical significance in thyroid carcinoma. J Clin Endocrinol Metab 88: 4407-4412, 2003.

17. Geering K: Function of FXYD proteins, regulators of $\mathrm{Na}$, K-ATPase. J Bioenerg Biomembr 37: 387-392, 2005.

18. Lubarski I, Karlish SJ and Garty H: Structural and functional interactions between FXYD5 and the $\mathrm{Na}^{+}-\mathrm{K}^{+}$-ATPase. Am J Physiol Renal Physiol 293: F1818-F1826, 2007.

19. Haas M, Askari A and Xie Z: Involvement of Src and epidermal growth factor receptor in the signal-transducing function of $\mathrm{Na}^{+} /$ $\mathrm{K}^{+}$-ATPase. J Biol Chem 275: 27832-27837, 2000.

20. Yu SP: $\mathrm{Na}^{+}, \mathrm{K}^{+}$-ATPase: the new face of an old player in pathogenesis and apoptotic/hybrid cell death. Biochem Pharmacol 66: 1601-1609, 2003. 